\title{
Still mesoendemic onchocerciasis in two Cameroonian community-directed treatment with ivermectin projects despite more than 15 years of mass treatment
}

Guy-Roger Kamga ${ }^{1,2,3^{*}}$, Fanny N. Dissak-Delon ${ }^{1,2,4}$, Hugues C. Nana-Djeunga ${ }^{2,5}$, Benjamin D. Biholong ${ }^{1}$, Stephen Mbigha-Ghogomu ${ }^{6}$, Jacob Souopgui ${ }^{4}$, Honorat G. M. Zoure ${ }^{7}$, Michel Boussinesq ${ }^{8}$, Joseph Kamgno ${ }^{2,5+}$ and Annie Robert ${ }^{3+}$

\begin{abstract}
Background: After more than a decade of community-directed treatment with ivermectin (CDTI) in Centre and Littoral Regions of Cameroon, onchocerciasis endemicity was still high in some communities according to the 2011 epidemiological evaluations. Some corrective measures were undertaken to improve the CDTI process and therefore reduce the burden of the disease. The objective of the present study was to assess the progress made towards the elimination of onchocerciasis in the Centre 1 and Littoral 2 CDTI projects where the worst performances were found in 2011. To this end, a cross-sectional survey was conducted in April 2015 in eight communities in two health districts (HD), Bafia in Centre 1 and Yabassi in Littoral 2, chosen because assessed at baseline and in 2011. All volunteers living for at least five years in the community, aged five years or more, underwent clinical and parasitological examinations. Individual compliance to ivermectin treatment was also assessed. Analyses of data were weighted proportionally to age and gender distribution in the population.

Results: In the Bafia and Yabassi HD, 514 and 242 individuals were examined with a mean age of 35.1 (standard deviation, SD: 20.7) and 44.6 (SD: 16.3) years, respectively. In the Bafia HD, the weighted prevalences varied from 24.4 to $57.0 \%$ for microfilaridermia and from 3.6 to $37.4 \%$ for nodule presence across the surveyed communities. The community microfilarial load (CMFL), expressed in microfilariae/skin snip (mf/ss), significantly dropped from 20.84-114. $50 \mathrm{mf} / \mathrm{ss}$ in 1991 to $0.31-1.62 \mathrm{mf} / \mathrm{ss}$ in 2015 in all the surveyed communities. In the Yabassi HD, the weighted prevalences varied from 12.3 to $59.3 \%$ for microfilaridermia and from 1.5 to $3.7 \%$ for nodule presence across the surveyed communities, while a significant drop was observed in CMFL, from 20.40-28.50 mf/ss in 1999 to 0.48-1.74 $\mathrm{mf} / \mathrm{ss}$ in 2015. The 2014 weighted therapeutic coverage of participants varied from $65.8 \%$ (95 \% Cl: 58.4-73.2) in Yabassi HD, to $68.0 \%$ (95 \% Cl: 63.3-72.7) in Bafia HD, with important variations among communities.

Conclusions: After more than 15 years of CDTI, onchocerciasis is still mesoendemic in the surveyed communities. Further studies targeting therapeutic coverage, socio-anthropological considerations of CDTI implementation and entomological studies would bring more insights to the persistence of the disease as observed in the present study.
\end{abstract}

Keywords: Onchocerciasis, Ivermectin, Persistence, Elimination, Bafia, Yabassi, Cameroon

\footnotetext{
* Correspondence: guyrogerkgr@gmail.com

${ }^{\dagger}$ Equal contributors

${ }^{1}$ Ministry of Public Health, Nº, Rue 3038 quartier du Lac, Yaoundé,

Cameroon

${ }^{2}$ Centre for Research on Filariasis and other Tropical Diseases (CRFilMT), P.O.

Box 5797, Yaoundé, Cameroon

Full list of author information is available at the end of the article
} 


\section{Background}

Onchocerciasis, better known as river blindness, is a debilitating insect-borne parasitic disease caused by Onchocerca volvulus and transmitted via the bites of blackflies of the genus Simulium. The larvae and pupae of the latter develop in fast-flowing and well-oxygenated streams and rivers. The prevalence of infection and disease in a community is therefore related to riverine breeding sites of the vector. The disease is endemic in 30 African countries, in Yemen and in localized foci in four Latin American countries. About 120 million people are at risk worldwide, with $99 \%$ of them living in Africa, and 37 million were infected in 1995, when the African Programme for Onchocerciasis Control (APOC) was launched [1, 2].

Adult $O$. volvulus average lifespan is estimated to 10-15 years $[3,4]$. Individual female worms produce daily thousands of microfilariae whose lifespan varies from 12 to 18 months. By invading the host dermis and eyes, live microfilariae interact with the host immune system, while dead microfilariae induce inflammatory responses, causing a variety of skin and ocular symptoms [5-7]. Infection leads to severe skin damage with unrelenting itching, visual impairment and blindness. Irreversible onchocercal blindness is ranked as the world's second leading infectious cause of preventable blindness after trachoma [8]. Besides its clinical impact, river blindness also has an important socio-economic impact on affected populations. It creates stigma [9] and generates and perpetuates poverty. Fear of the disease often prompted people to abandon fertile lands which in turn led to an increase in poverty and famine, making the disease a major obstacle to socioeconomic development. The agricultural productivity is therefore hindered, generating massive economic losses and imposing a disproportionate disease burden in poor rural communities [10].

Ivermectin is currently the only known effective and safe drug used for mass treatments against onchocerciasis. However, since this drug has a limited macrofilaricidal activity, treatments must be repeated for more than 15 years. The control of onchocerciasis has been quite successful with the implementation of Community Directed Treatment with Ivermectin (CDTI). This strategy, proposed by the World Health Organization (WHO) through APOC, has significantly improved Ivermectin treatment coverage [11-13]. While this drug has been administrated twice or four times a year in the small and well-delineated endemic communities of the Americas, single doses have been given yearly in the much larger foci in African endemic countries [14, 15]. As a consequence, the programmes in the Americas are highly successful and are attaining the onchocerciasis elimination point [16-20], while this disease remains a public health problem in Africa. Nevertheless, new evidence points exist towards the possibility of successful elimination of river blindness in Africa using ivermectin solely $[21,22]$. Indeed, a spectacular decrease in microfilaridermia prevalence below $1 \%$ was reported in Mali and Senegal [22], as well as in some CDTI-project in the APOC countries [23, 24]. However, despite more than 20 years of disease control, onchocerciasis remains a major concern for several endemic countries, including Cameroon [25]. Indeed, recent WHO/APOC surveys conducted in 2011 revealed onchocerciasis prevalences above $60 \%$ in the Centre 1, Littoral 2 and West CDTIprojects in Cameroon [24]. The reasons for the persistence of the infection are yet to be elucidated, and it is not clear whether this is due to low treatment coverage, systematic non-compliance of a proportion of the population, or suboptimal response of the parasite to ivermectin [26-28]. These poor results led to the implementation of some corrective measures (frequent and regular supportive supervision, data quality audit, community self-monitoring and a better drug management) by the National Onchocerciasis Control Programme to improve the CDTI performances.

The objective of the present survey was, therefore, to assess the progress made towards the elimination of onchocerciasis in the Centre 1 and Littoral 2 CDTI projects where the worst performances were found in 2011.

\section{Methods}

\section{Study area and selection of communities}

The present study was conducted in the Bafia $\left(4^{\circ} 45^{\prime} 00^{\prime \prime}\right.$ $\left.\mathrm{N}, 11^{\circ} 14^{\prime} 00^{\prime \prime} \mathrm{E}\right)$ and Yabassi $\left(4^{\circ} 27^{\prime} 16^{\prime \prime} \mathrm{N}, 9^{\circ} 57^{\prime} 56^{\prime \prime} \mathrm{E}\right)$ health districts (HD), belonging to the Centre 1 and Littoral 2 CDTI projects, respectively.

The Bafia HD is located in the Mbam and Inoubou Division (Centre Region), at $120 \mathrm{~km}$ north from Yaoundé, the political capital of Cameroon. In 2014, its population was 226,073 inhabitants, based on a census conducted by community-directed distributors (CDD). The altitude of this region varies from 1,100 to $1,300 \mathrm{~m}$. It is a forest-savanna transition zone, irrigated by many fast-flowing rivers including Sanaga and its tributaries, as well as the Mbam and Noun rivers. The main activities of inhabitants are agriculture (mainly cocoa), fishing and sand mining.

The Yabassi HD is located in the Nkam Division (Littoral Region), at $100 \mathrm{~km}$ north-east from Douala, the economic capital of the country. According to the 2014 CDD census, its population was 21,459 inhabitants. The relief is undulating, showing an alternation of valleys and plains. Altitude of the region varies from 10 to 800 $\mathrm{m}$. This district is irrigated by many fast-flowing rivers comprising Nkam, Dibamba, Mabombé, Njanga and Mahé which are favorable to blackfly breeding. The vegetation is mainly dense humid forest. Agriculture is the main activity, interesting at least $60 \%$ of inhabitants. 


\section{Baseline and follow-up surveys}

Surveyed communities were selected according to the availability of baseline data and the results of the 2011 follow-up survey carried out by the National Onchocerciasis Control Programme (NOCP) with the support of APOC (NOCP, unpublished report). The prevalence and intensity of infection (nodules and microfilaridermia) had also been assessed in 1991-1993 by an IRD-Centre Pasteur du Cameroun team in seven communities of the Bafia HD [29], and in 1999 in seven communities of the Yabassi HD (Kamgno, unpublished report). From these 14 communities, four (Balamba II, Biatsota, Ngongol and Tsékané) in the Bafia HD and four (Bodiman, Bonadissake, Ndogpoo and Nkongmalan) in the Yabassi HD, with the highest microfilaridermia prevalence and/or community microfilarial load (CMFL), were selected for the present survey (Tables 1 and 2; Fig. 1).

\section{History of mass treatment with ivermectin}

In the Bafia HD, a clinical trial was conducted between 1994 and 1998, with mass treatment carried out in some communities [30, 31]. However, according to the NOCP, CDTI started in 1999 and in 2000 in Littoral 2 and Centre 1 projects, respectively [32]. So these communities received 16 rounds and 15 rounds of mass drug administration, respectively. The therapeutic coverage achieved in each project is illustrated in Fig. 2. Even though the two projects achieved the treatment coverage threshold for control (65\%) during the last 13 years, none of them reached $80 \%$ treatment coverage, the threshold for elimination, although a significant improvement has been achieved since 2012 .

\section{Study design and patients}

A cross-sectional survey was conducted in April 2015 in eight communities of the Bafia and Yabassi health districts, nine months after the previous annual ivermectin distribution. All individuals, permanent residents or who had already lived for at least five years in the community and aged five years or more were eligible for this survey. All volunteers underwent clinical and parasitological

Table 1 Onchocerciasis burden in four communities of Bafia health district at baseline and during the 2011 survey, after 11 years of CDTI

\begin{tabular}{|c|c|c|c|c|c|c|}
\hline \multirow[t]{2}{*}{ Village } & \multicolumn{3}{|c|}{ Baseline data (1991-1993) } & \multicolumn{3}{|c|}{ Follow-up survey (2011) } \\
\hline & $\bar{N}$ & $\begin{array}{l}\text { Weighted } \mathrm{mf} \\
\text { prevalence (\%) }\end{array}$ & $\begin{array}{l}\mathrm{CMFL} \\
(\mathrm{mf} / \mathrm{ss})\end{array}$ & $\bar{N}$ & $\begin{array}{l}\text { Weighted } \mathrm{mf} \\
\text { prevalence (\%) }\end{array}$ & $\begin{array}{l}\text { CMFL } \\
(\mathrm{mf} / \mathrm{ss})\end{array}$ \\
\hline Tsékané & 150 & 90.8 & 20.84 & 204 & 47.1 & 1.44 \\
\hline Balamba II & 167 & 83.7 & 26.40 & 212 & 61.0 & 4.72 \\
\hline Ngongol I & 129 & 92.8 & 90.31 & 237 & 64.0 & 2.54 \\
\hline Biatsota & 150 & 94.0 & 114.50 & 227 & 67.6 & 3.26 \\
\hline
\end{tabular}

Abbreviations: $N$ number examined, $m f$ microfilaria, CMFL community microfilarial load (microfilariae/skin snip)
Table 2 Onchocerciasis burden in four communities of Yabassi health district at baseline and during the 2011 survey

\begin{tabular}{|c|c|c|c|c|c|c|}
\hline \multirow[t]{2}{*}{ Village } & \multicolumn{3}{|c|}{ Baseline data (1999) } & \multicolumn{3}{|c|}{ Follow-up survey (2011) } \\
\hline & $N$ & $\begin{array}{l}\text { Weighted mf } \\
\text { prevalence (\%) }\end{array}$ & $\begin{array}{l}\text { CMFL } \\
\text { (mf/ss) }\end{array}$ & $N$ & $\begin{array}{l}\text { Weighted } \mathrm{mf} \\
\text { prevalence (\%) }\end{array}$ & $\begin{array}{l}\text { CMFL } \\
(\mathrm{mf} / \mathrm{ss})\end{array}$ \\
\hline Bonadissake & 58 & 79.3 & 20.4 & & & \\
\hline Ndogpoo & 39 & 87.2 & 24.2 & & & \\
\hline Nkongmalan & 84 & 92.2 & 28.5 & & & \\
\hline Bodiman & 81 & 90.1 & 26.5 & 112 & 65.2 & 2.96 \\
\hline
\end{tabular}

Abbreviations: $N$ number examined, $m f$ microfilaria, CMFL community microfilarial load (microfilariae/skin snip)

examinations. In addition, individual compliance to ivermectin treatment was also assessed.

\section{Clinical examination}

Each participant was examined for skin disease and nodules. The searched cutaneous signs were depigmentation, onchodermatitis (acute, chronic and lichenified), hanging groin and skin atrophy. Participants were scored as 'positive' or 'negative' to each cutaneous sign. Nodule palpation was performed in a closed but wellilluminated room. Qualified and certified staff performed the palpation on partially disrobed participants while paying particular attention to bony prominences of the torso, iliac crests and upper trochanter of the femurs. Onchocercal nodules were identified clinically as mobile masses beneath the skin, firm and painless [33-35]. Results were ranked as 'positive' or 'negative', and if positive, the number and location of all palpable onchocercal nodules were recorded.

\section{Parasitological examination}

Immediately following the nodule palpation, two skin snips were taken from each posterior iliac crest using a 2 $\mathrm{mm}$ corneoscleral punch (Holth-type). The skin samples were immediately placed, separately, into wells of microtitration plates containing a sterile normal saline solution. After $24 \mathrm{~h}$ incubation at room temperature, the skin snips were removed and the fluid from each well was examined under low magnification $(40 x)$ by trained laboratory technicians [36]. For positive results, the microfilariae were counted and the individual microfilarial densities were expressed as the arithmetic mean number of microfilariae in the two skin snips $(\mathrm{mf} / \mathrm{ss})$.

\section{Assessment of the individual compliance to ivermectin mass treatment}

Individual compliance to ivermectin mass treatment was assessed by asking each participant if he/she swallowed ivermectin tablets during each of the previous five years (including the last CDTI-campaign). Ivermectin tablets were presented to the participants to make sure that the interview was targeting the right 

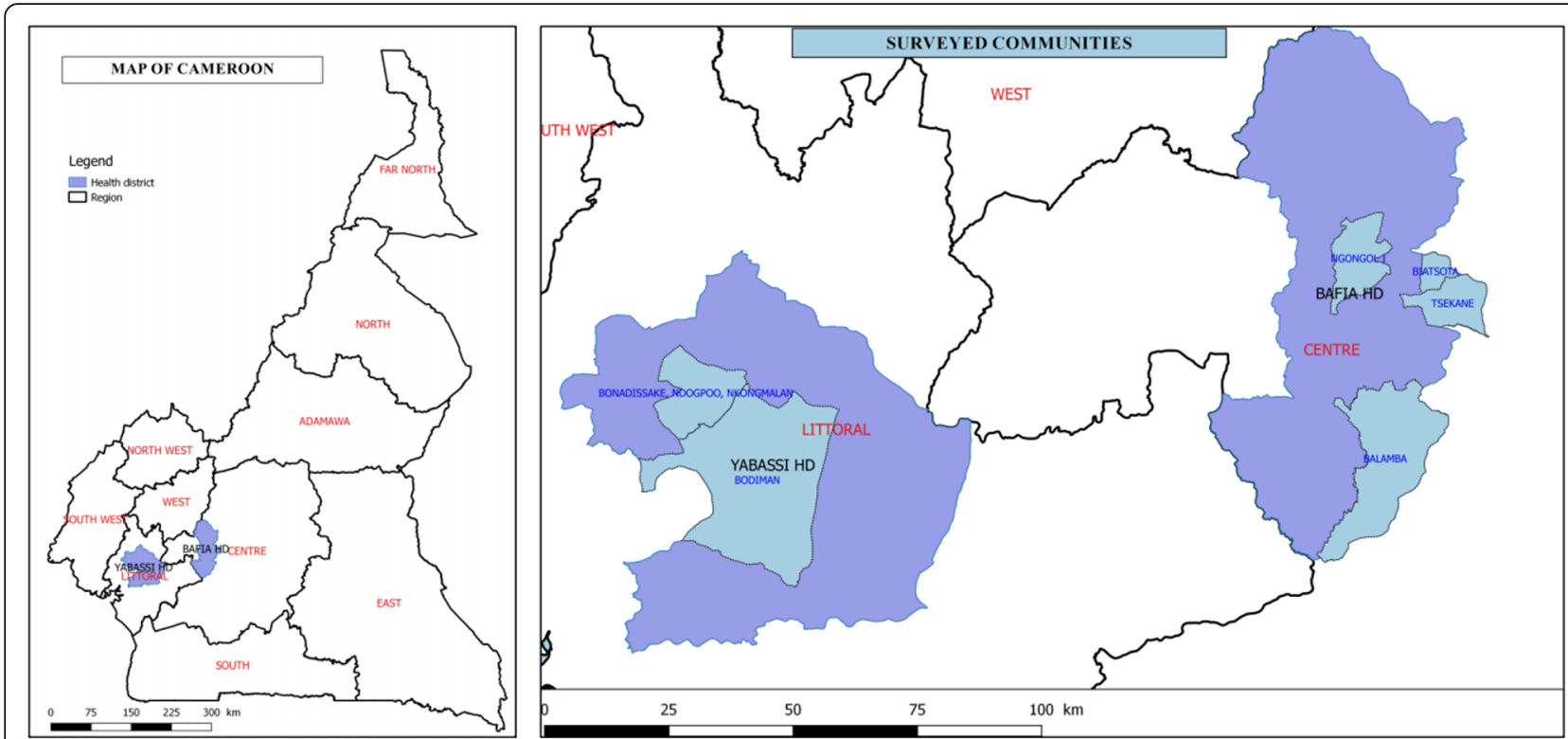

Fig. 1 Map of Cameroon showing the study areas and communities surveyed

treatment. The participant answers were recorded on an individual form as "yes" or "no" for each of the last five years.

\section{Data analysis}

All relevant data (clinical signs, nodule, $\mathrm{mf}$ count, and compliance to ivermectin mass treatment) were recorded into a purpose-built Microsoft Access database and subsequently exported into STATA 13 for statistical analysis. All analyses were weighted proportionally to age- and gender distribution in the population, according to 2015 national demographic data projections [37]. Cutaneous signs, nodules and microfilaridermia prevalences were expressed as the proportion of infected or affected individuals with the $95 \%$ exact confidence interval (CI). Each community was classified according to the prevalence of microfilaridermia as hypoendemic (prevalence $<35 \%$ ), mesoendemic (35\% prevalence $<60 \%$ ) or hyperendemic (prevalence $\geq 60 \%$ ) [38]. When the microfilarial count was positive, the intensity of infection was computed as the arithmetic mean and its $95 \%$ CI. The community microfilarial load (CMFL), defined as the

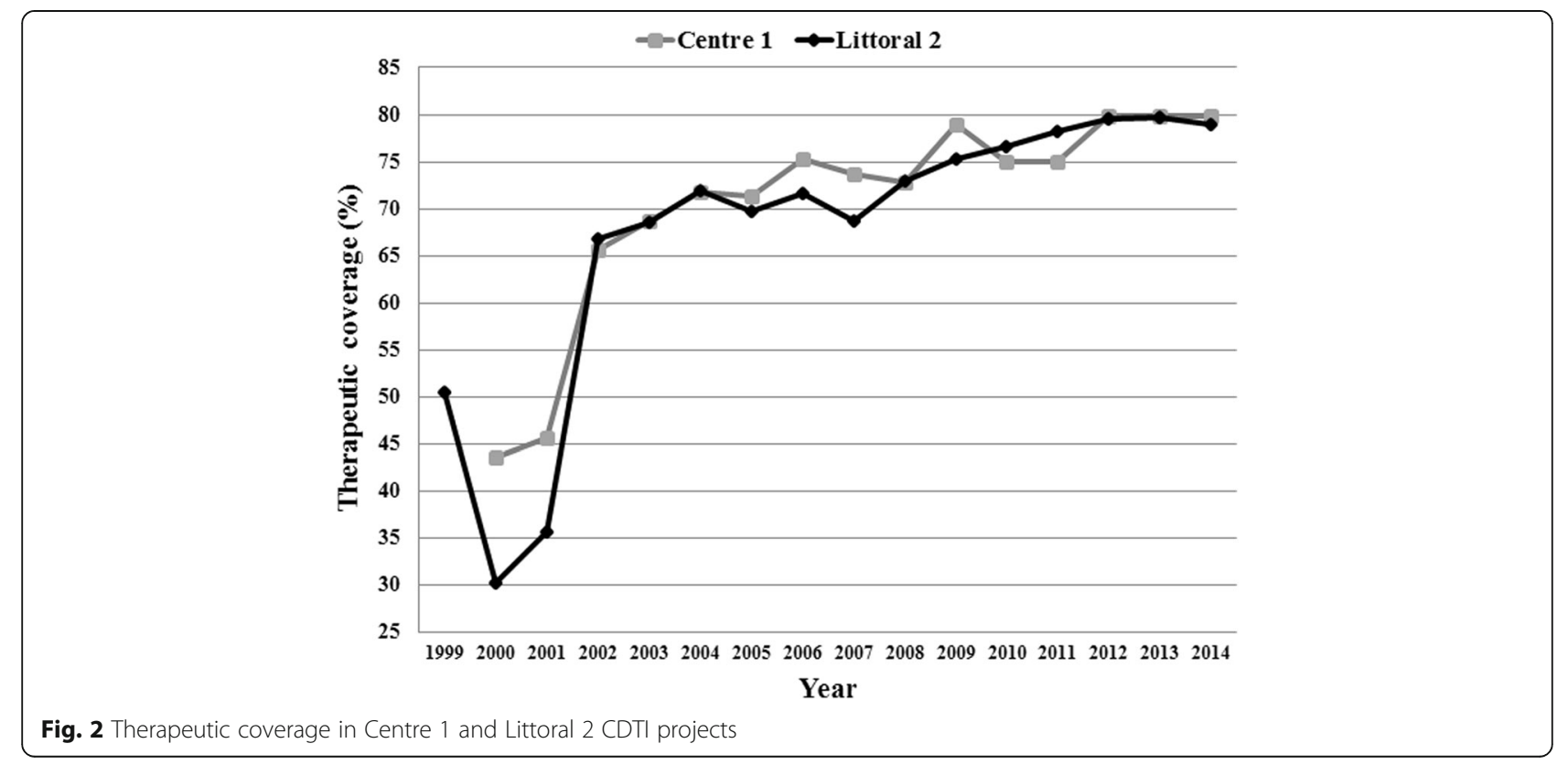


geometric mean number of microfilariae per skin snip among adults aged 20 years or more, was calculated using a $\log (\mathrm{x}+1)$-transformation:

$$
\text { CMFL }=\mathrm{e}^{\frac{1}{\mathrm{~N}} \sum \ln (\mathrm{x}+1)}-1
$$

where $\mathrm{x}$ is the individual microfilarial density, and $\mathrm{N}$ the total number of individuals aged 20 years and above. Proportions were compared using Chi-square tests. Mean intensities of infection were compared between age- and gender subgroups using ANOVA with F-tests or $t$-tests. A $P$-value $<0.05$ was considered as statistically significant.

\section{Results}

In the two HD, 514 and 242 individuals were examined. Mean ages were 35.1 (SD: 20.7) and 44.6 (SD: 16.3) years, respectively. The sex ratio was slightly femalebiased in the Bafia HD (female proportion of $51.8 \%$ ), but was male-biased in the Yabassi HD (female proportion equal to $45.9 \%$ ).

\section{Prevalence and intensity of infection}

In Bafia $\mathrm{HD}$, weighted prevalences varied from 24.4 to $57.0 \%$ for microfilaridermia and 3.6 to $37.4 \%$ for nodule prevalence across the surveyed communities. Men were more affected than women, both for microfilaridermia (47.5 vs $36.5 \% ; \chi^{2}=6.4, d f=1, P=0.03$ ) and nodule presence (27.1 vs $10.5 \%$; $\chi^{2}=23.8, d f=1, P<0.001$ ). The communities Biatsota and Ngongol I had the highest burden, both for microfilaridermia and nodule prevalence, and were ranked as mesoendemic according to the microfilaridermia prevalence. Balamba II and Tsékané were ranked as hypoendemic although still presenting with high prevalences after 15 years of treatment (Table 3 ).
Across age groups, no significant differences in microfilaridermia prevalence were observed, while nodule prevalence increased with age. Arithmetic mean of microfilaridermia among positive cases was higher in younger participants (9-19 years) and decreased with age, thus displaying an opposite trend to the one observed for nodule prevalence (Table 4).

A significant reduction in prevalence was observed in all communities when comparing the present data to baseline data $\left(\chi^{2}=222.6, d f=9, P<0.001\right)$ (Fig. 3$)$. The CMFL in all the surveyed communities also significantly dropped by $98-99 \%$ from $20.84-114.50 \mathrm{mf} / \mathrm{ss}$ in 1991 to $0.31-1.62 \mathrm{mf} / \mathrm{ss}$ in 2015 (ANOVA: $F_{(1,3)}=$ 131.6, $P<0.001$ ) (Fig. 4).

In Yabassi HD, weighted prevalences varied from 12.3 to $59.3 \%$ for microfilaridermia and from 1.5 to $3.7 \%$ for nodules. Men were more affected than women, both for microfilaridermia (48.7 vs 38.4\%; $\chi^{2}=2.6, d f=1, P=$ 0.17 ) and nodule presence ( 4.5 vs $0.7 \% ; \chi^{2}=3.3, d f=1$, $P=0.07)$; however, the differences were not statistically significant. Onchocercal skin lesions were more frequent in two communities (Bonadissake and Ndogpoo) where lower limb depigmentation, acute and chronic onchodermatitis were found (Table 3). The arithmetic mean of microfilarial load decreased with age while the mean number of nodules increased (Table 4).

A significant reduction in prevalence was found in all communities when comparing baseline to the follow-up data in $2015\left(\chi^{2}=107.6, d f=9, P<0.001\right)$ (Fig. 5). A significant drop in CMFL by $94-98 \%$, was also observed, from $20.40-28.50$ in 1999 to $0.48-1.74 \mathrm{mf} / \mathrm{ss}$ in 2015 (ANOVA: $F_{(1,3)}=1554.7, P<0.001$ ) (Fig. 6). Most palpable nodules were localized in the pelvic grid, the back, the chest and the knee with half of them found in the pelvic grid (Fig. 7).

Table 3 Parasitological load and clinical signs of onchocerciasis within each community in the present survey of 2015

\begin{tabular}{|c|c|c|c|c|c|c|}
\hline \multirow[t]{2}{*}{ District and community } & \multirow[b]{2}{*}{ N } & \multicolumn{3}{|c|}{ Microfilaridermia examination } & \multicolumn{2}{|c|}{ Clinical examination weighted prevalence (\%) } \\
\hline & & Weighted prevalence (\%) & CMFL (mf/ss) & Status & Nodule & Cutaneous sign \\
\hline \multicolumn{7}{|l|}{ Bafia } \\
\hline Balamba II & 138 & 24.4 & 0.51 & Hypoendemic & 3.6 & 1.1 \\
\hline Biatsota & 94 & 45.8 & 1.04 & Mesoendemic & 37.4 & 7.0 \\
\hline Ngongol I & 186 & 57.0 & 1.62 & Mesoendemic & 23.9 & 1.5 \\
\hline Tsékané & 96 & 26.4 & 0.31 & Hypoendemic & 7.2 & 3.0 \\
\hline Total & 514 & 41.6 & & Mesoendemic & 18.1 & 2.3 \\
\hline \multicolumn{7}{|l|}{ Yabassi } \\
\hline Bodiman & 64 & 59.3 & 1.39 & Mesoendemic & 3.7 & 2.8 \\
\hline Bonadissake & 41 & 12.3 & 0.48 & Hypoendemic & 1.6 & 22.4 \\
\hline Ndogpoo & 80 & 46.7 & 1.10 & Mesoendemic & 1.5 & 10.9 \\
\hline Nkongmalan & 57 & 47.7 & 1.74 & Mesoendemic & 3.5 & 4.6 \\
\hline Total & 242 & 43.8 & & Mesoendemic & 2.7 & 9.3 \\
\hline
\end{tabular}


Table 4 Microfilaria and nodule status across age groups in the present survey of 2015

\begin{tabular}{|c|c|c|c|c|c|c|c|c|}
\hline \multirow[t]{2}{*}{ District } & \multirow{2}{*}{$\begin{array}{l}\text { Age categories } \\
\text { (years) }\end{array}$} & \multirow[b]{2}{*}{$N$} & \multicolumn{3}{|c|}{ Microfilaria status } & \multicolumn{3}{|c|}{ Nodule status } \\
\hline & & & $\overline{M f+(n)}$ & $\begin{array}{l}\text { Weighted } \\
\text { prevalence (\%) }\end{array}$ & $\begin{array}{l}\text { Weighted mean } \pm \mathrm{SD} \\
\text { of } \mathrm{mf} \text { in carriers }\end{array}$ & $\overline{N o d+(n)}$ & $\begin{array}{l}\text { Weighted } \\
\text { prevalence (\%) }\end{array}$ & $\begin{array}{l}\text { Weighted mean } \pm S D \\
\text { of nodules in carriers }\end{array}$ \\
\hline \multirow[t]{8}{*}{ Bafia } & $5-9$ & 56 & 19 & 34.0 & $20.5 \pm 27.7$ & 9 & 16.1 & $1.7 \pm 0.7$ \\
\hline & $10-19$ & 94 & 47 & 50.0 & $24.9 \pm 47.6$ & 9 & 9.6 & $2.2 \pm 1.4$ \\
\hline & $20-29$ & 76 & 32 & 41.5 & $10.9 \pm 22.4$ & 12 & 14.9 & $2.1 \pm 1.1$ \\
\hline & 30-39 & 70 & 28 & 40.0 & $13.8 \pm 24.0$ & 23 & 32.5 & $2.6 \pm 2.1$ \\
\hline & $40-49$ & 69 & 24 & 34.7 & $13.5 \pm 24.6$ & 21 & 30.4 & $2.6 \pm 2.3$ \\
\hline & $50-59$ & 70 & 26 & 37.2 & $6.6 \pm 9.3$ & 17 & 24.5 & $2.8 \pm 2.0$ \\
\hline & $60+$ & 79 & 20 & 25.4 & $7.6 \pm 12.5$ & 24 & 30.0 & $2.5 \pm 2.6$ \\
\hline & Total & 514 & 196 & 41.6 & $17.9 \pm 35.5$ & 115 & 18.1 & $2.4 \pm 1.8$ \\
\hline \multirow[t]{8}{*}{ Yabassi } & $5-9$ & 0 & - & - & - & - & - & - \\
\hline & 10-19 & 14 & 7 & 50.0 & $21.4 \pm 21.3$ & 0 & 0 & 0 \\
\hline & $20-29$ & 35 & 13 & 36.6 & $16.5 \pm 29.3$ & 0 & 0 & 0 \\
\hline & $30-39$ & 47 & 23 & 48.9 & $16.1 \pm 26.5$ & 1 & 2.1 & 1 \\
\hline & $40-49$ & 48 & 17 & 35.4 & $5.1 \pm 6.9$ & 3 & 6.3 & $1.7 \pm 0.6$ \\
\hline & $50-59$ & 51 & 28 & 54.9 & $11.2 \pm 19.4$ & 4 & 8.0 & $2 \pm 0.8$ \\
\hline & $60+$ & 47 & 21 & 44.7 & $7.3 \pm 12.5$ & 2 & 4.1 & $2.5 \pm 0.7$ \\
\hline & Total & 242 & 109 & 43.8 & $14.2 \pm 22.6$ & 10 & 2.7 & $1.8 \pm 0.7$ \\
\hline
\end{tabular}

Abbreviations: $N$ number examined, $m f$ microfilaria, $M f+(n)$ number with microfilaria positive skin snip, Nod+ (n) number of nodule carriers, $S D$ standard deviation an each age category, the indices were adjusted on sex; in the total populations, indices were adjusted on sex and age

\section{Compliance to ivermectin mass treatments in surveyed communities}

The weighted therapeutic coverage in 2014 varied from 65.8 \% (95 \% CI: 58.4-73.2) to 68.0 \% (95 \% CI: 63.3-72.7) in the surveyed communities from Yabassi HD and Bafia HD, respectively, with important variations across communities. A variation was also observed in the compliance to ivermectin over five years, from 39.9 \% (95 \% CI: $35.2-$ 44.6) in Bafia HD to 54.0 \% (95 \% CI: 46.6-61.4) in Yabassi HD. The adherence to treatment increased significantly with age since more than $75 \%$ of participants aged 40 years and above declared having taken the treatment each year during the last five years, whereas only $31 \%$ of individuals aged $10-29$ years did so $\left(\chi^{2}=234.6, d f=\right.$

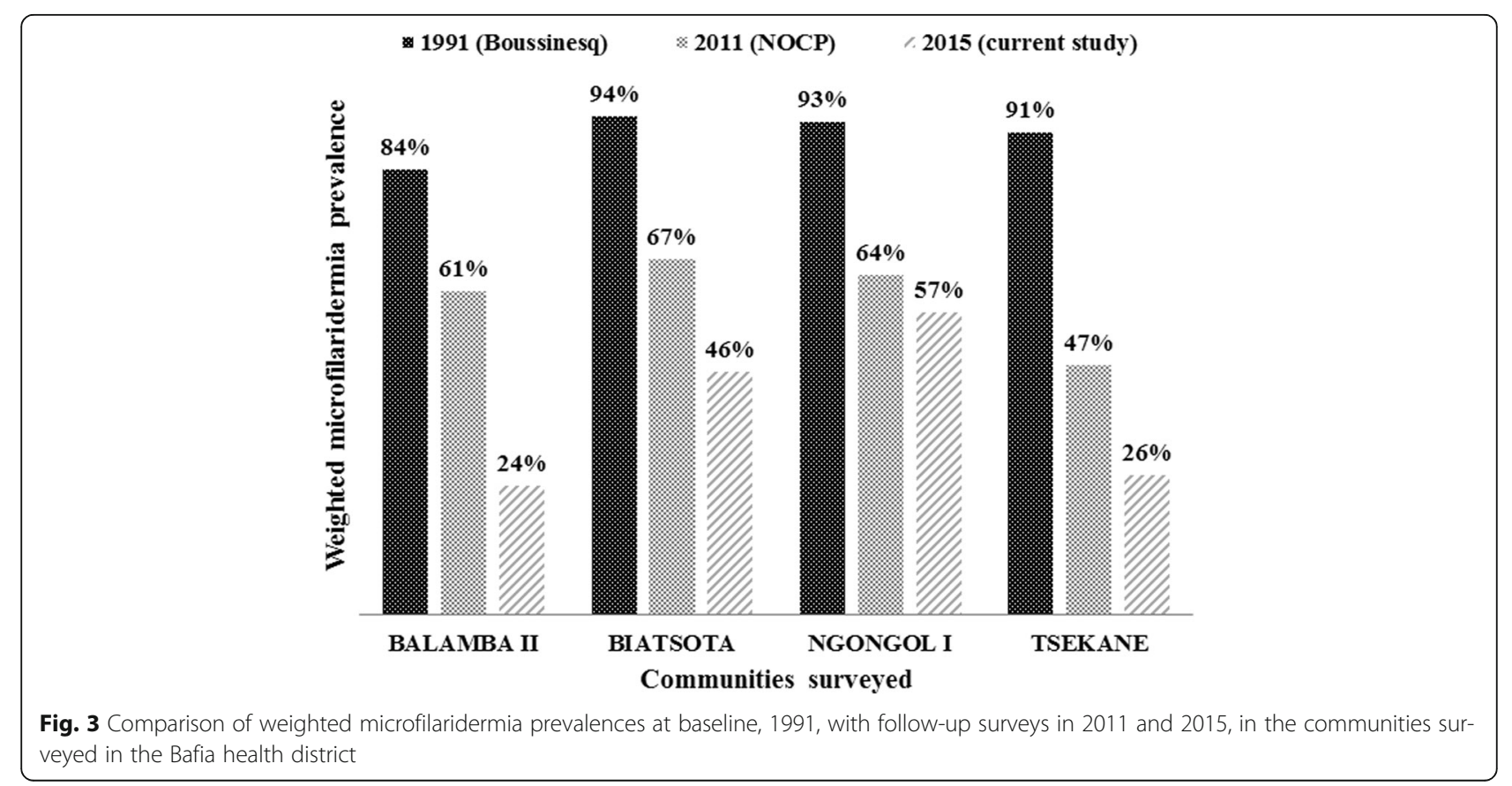




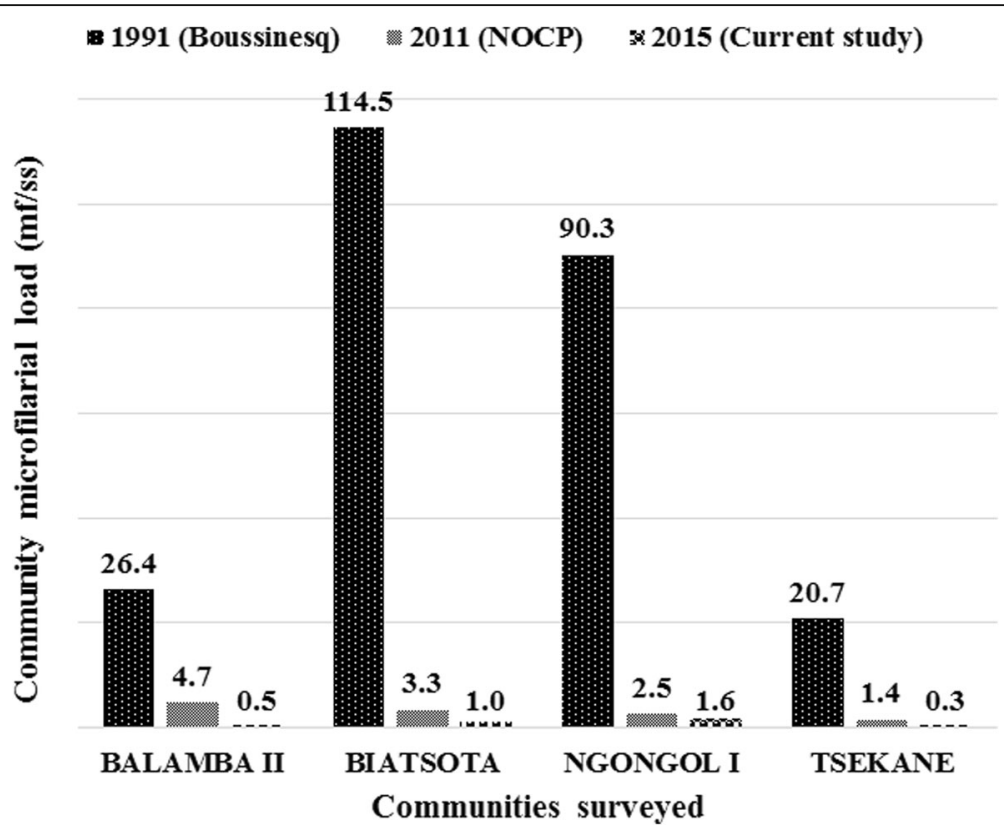

Fig. 4 Comparison of community microfilarial load at baseline, 1991, with follow-up surveys in 2011 and 2015, in the communities surveyed in the Bafia health district. Abbreviations: $\mathrm{mf}$, microfilaria; ss, skin snip

$30, P<0.001)$. More than one out of five participants in Bafia HD (21.3\%; $95 \%$ CI: 17.1-25.5) and Yabassi HD (22.0\%; 95 \% CI: 15.3-28.6) declared that they had not taken the treatment during the last five years (Figs. 8 and 9). The microfilaridermia prevalence was associated with treatment compliance in Bafia HD $\left(\chi^{2}=14.0, d f=5, P=\right.$ $0.016)$, but not in Yabassi HD $\left(\chi^{2}=10.5, d f=5, P=\right.$
0.062), whereas its intensity was significantly negatively associated with compliance to treatment in both districts (ANOVA: $\left.F_{(5,299)}=5.95, P<0.001\right)$ as shown in Fig. 10 .

\section{Discussion}

The objective of this study was to assess the progress made towards the elimination of onchocerciasis in the

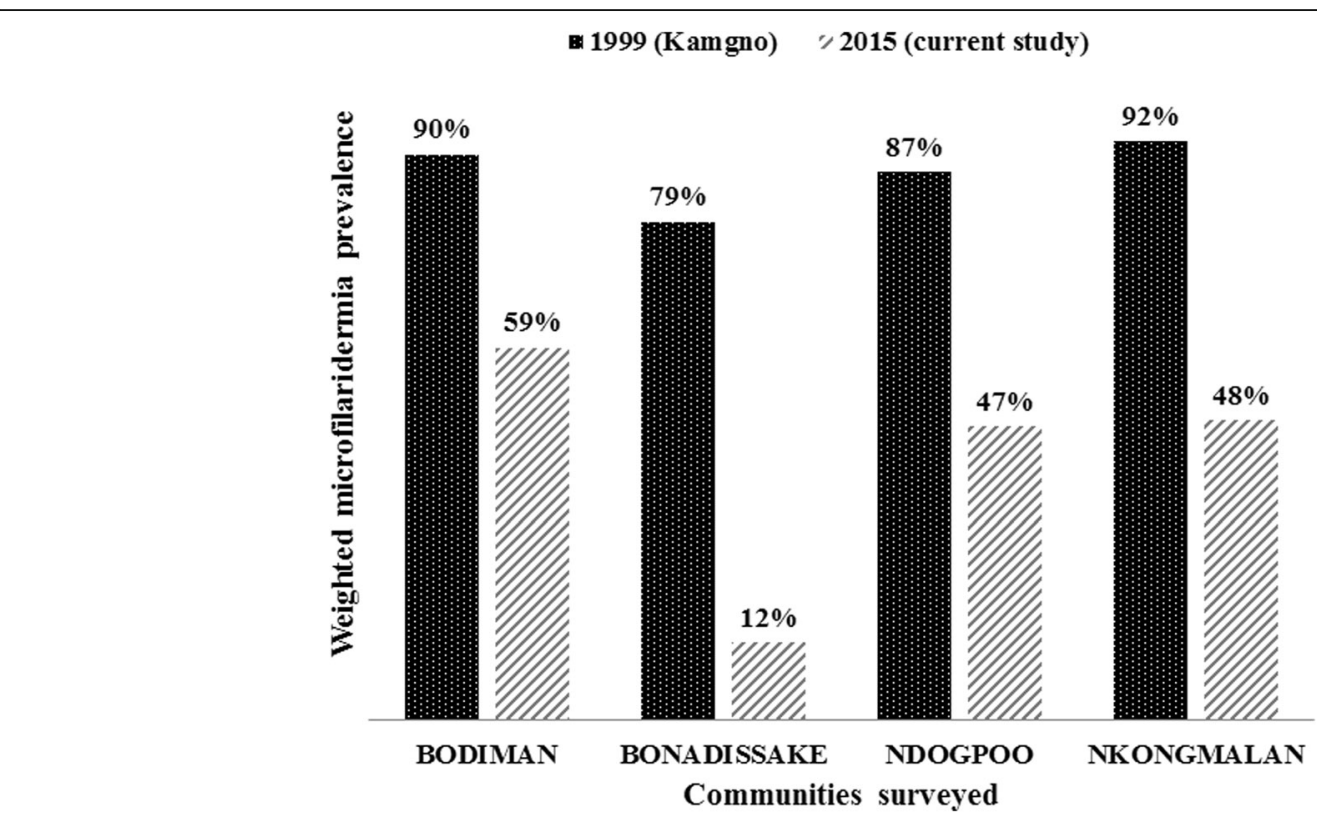

Fig. 5 Comparison of weighted microfilaridermia prevalences at baseline, 1999, with follow-up surveys in 2015, in the communities surveyed in the Yabassi health district 
1999 (Kamgno) $\quad \% 2015$ (Current study)

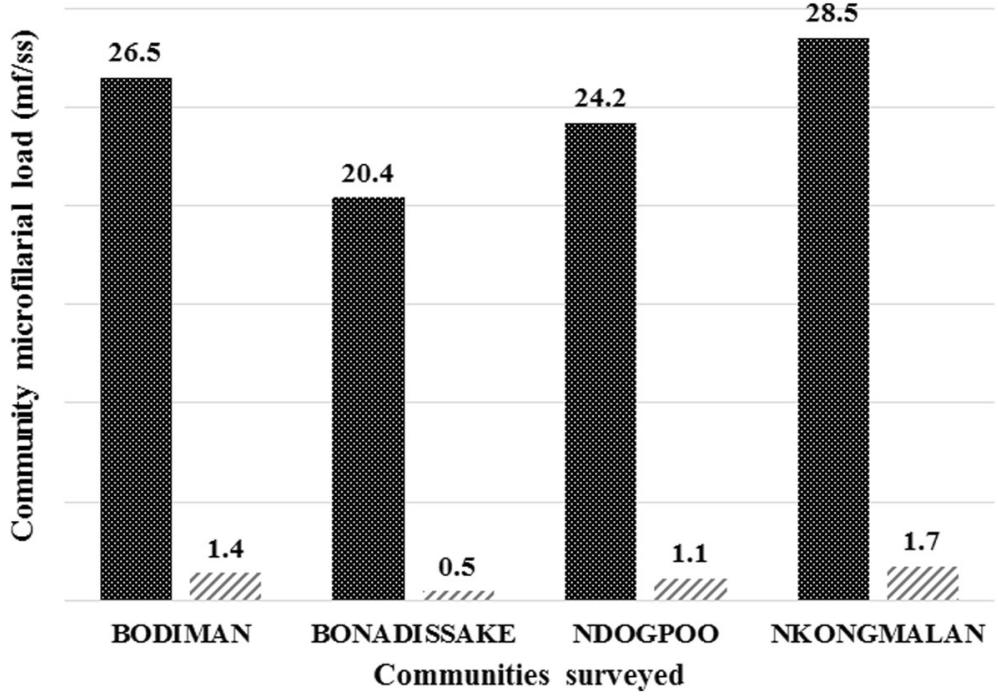

Fig. 6 Comparison of community microfilarial load at baseline, 1999, with follow-up surveys in 2015, in the communities surveyed in the Yabassi health district. Abbreviations: mf, microfilaria; ss, skin snip

Centre 1 and Littoral 2 CDTI projects where high prevalence and intensity of infection were found in 2011. In 2015, after more than 15 years of mass treatment, we observed a reduction in microfilaridermia prevalence, but values were still above the expected level $(\leq 20 \%$ for a pretreatment endemicity $\geq 80 \%$ assuming a therapeutic coverage of $65 \%)[39,40]$. Indeed, onchocerciasis is still mesoendemic in many surveyed communities especially in those closest to fast-flowing rivers. Blackfly breeding sites located a few kilometres from Biatsota, Ngongol I and Bodiman contribute to maintain high vector densities and continuing transmission as was previously demonstrated for first-line communities [29]. The same communities had the highest prevalences of nodules in the two health districts. Furthermore, the high microfilaridermia and nodule prevalences observed in less than 10-year-old children, born after the launch of the programme, are a strong evidence of ongoing active transmission which could later be confirmed by entomological studies. In addition to the parasite burden, the persistence of the disease can also be explained by the low adherence to treatment as only 40 and $54 \%$

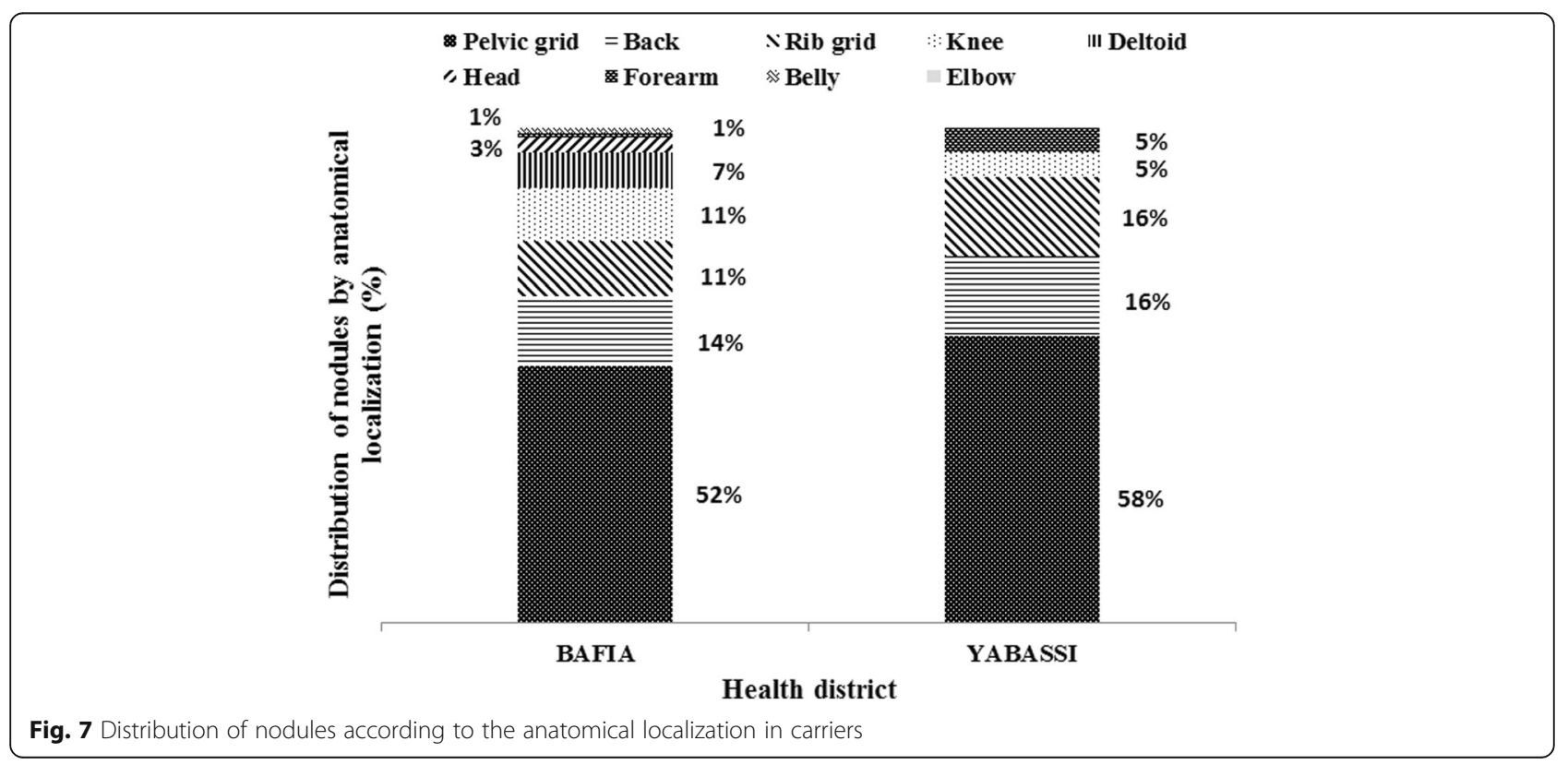




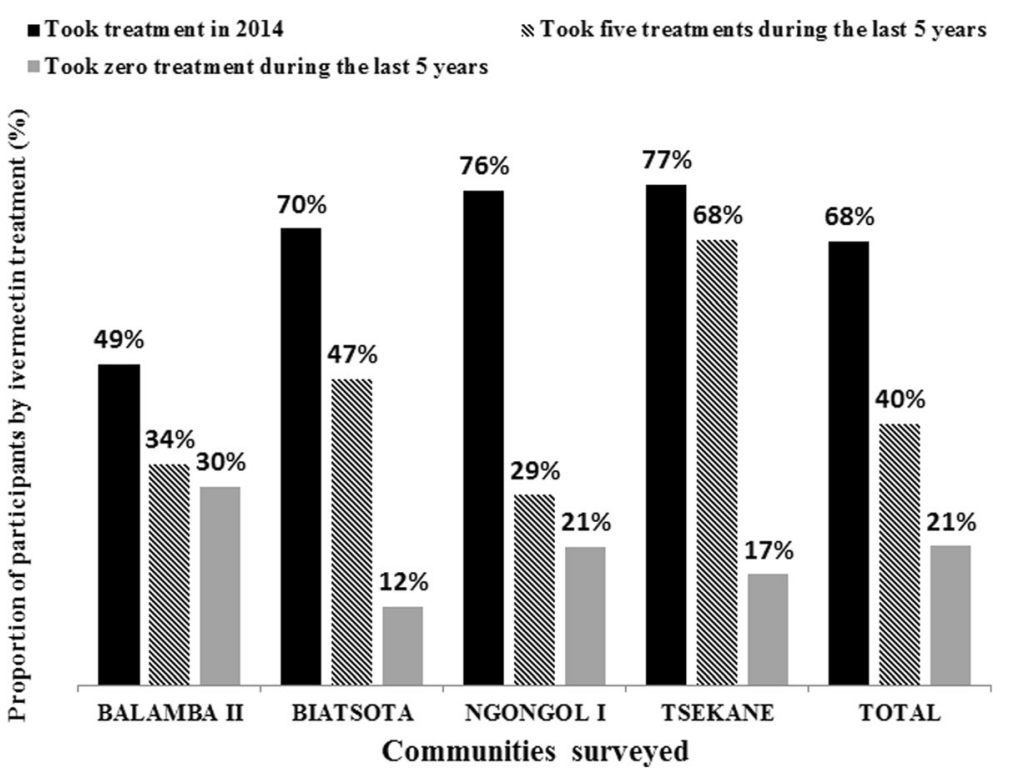

Fig. 8 Proportion of participants according to ivermectin treatment in the Bafia health district

of participants in Bafia HD and Yabassi HD, respectively, declared having taken five treatments during the last five years. At the same time, about $20 \%$ of the participants had taken no treatment during that period. With the observed treatment coverage, the likelihood for the programme to achieve elimination of the disease by 2025 is quite low. Even though this survey was conducted nine months after the previous treatment, we believe that our results regarding the therapeutic coverage and the compliance are reliable because ivermectin tablets are special, by both their physical presentation (small and white) and their delivery strategy. So, the likelihood to confuse them with other drugs or interventions is quite low. Previous studies have reported accurate recall of populations when compared to the data from CDTI collected in treatment registry [41-43].

Despite the high $\mathrm{mf}$ prevalences observed in both districts, the intensity of infection had dramatically decreased in 2015, with CMFL below $2 \mathrm{mf} / \mathrm{ss}$ in all communities, as compared to baseline data. Even when compared to 2011, the CMFL dropped by half in almost all surveyed communities. Furthermore, the arithmetic mean number of microfilariae per skin snip among positive cases was found to be related to compliance to treatment. Thus it could be

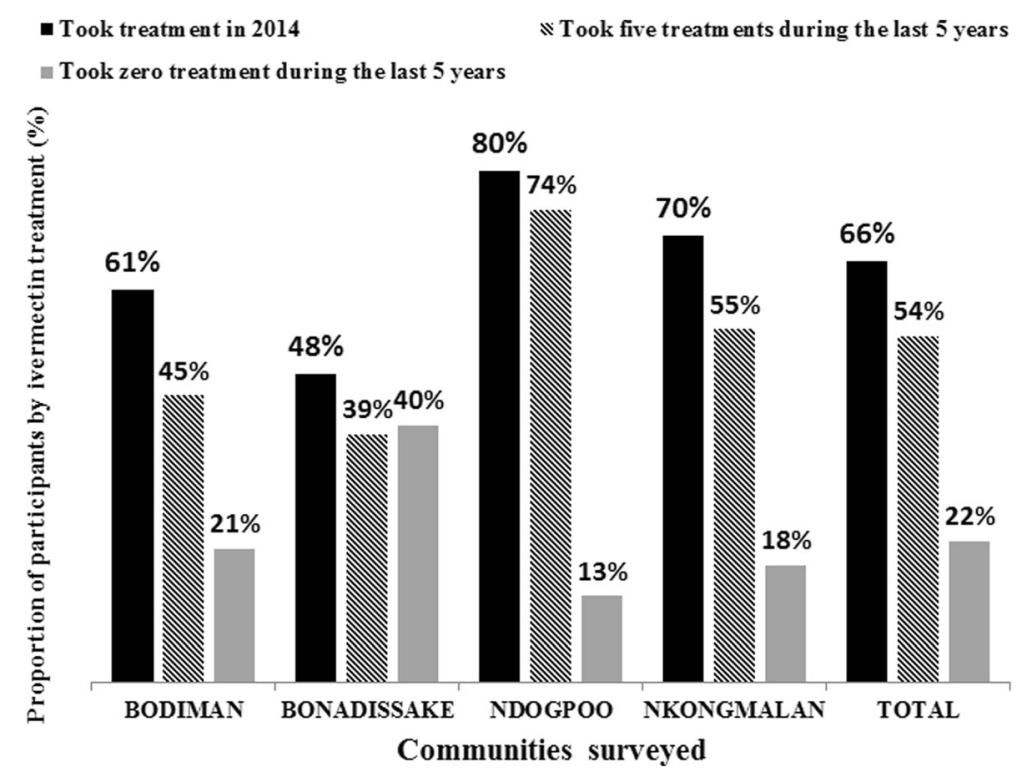

Fig. 9 Proportion of participants according to ivermectin treatment in the Yabassi health district 


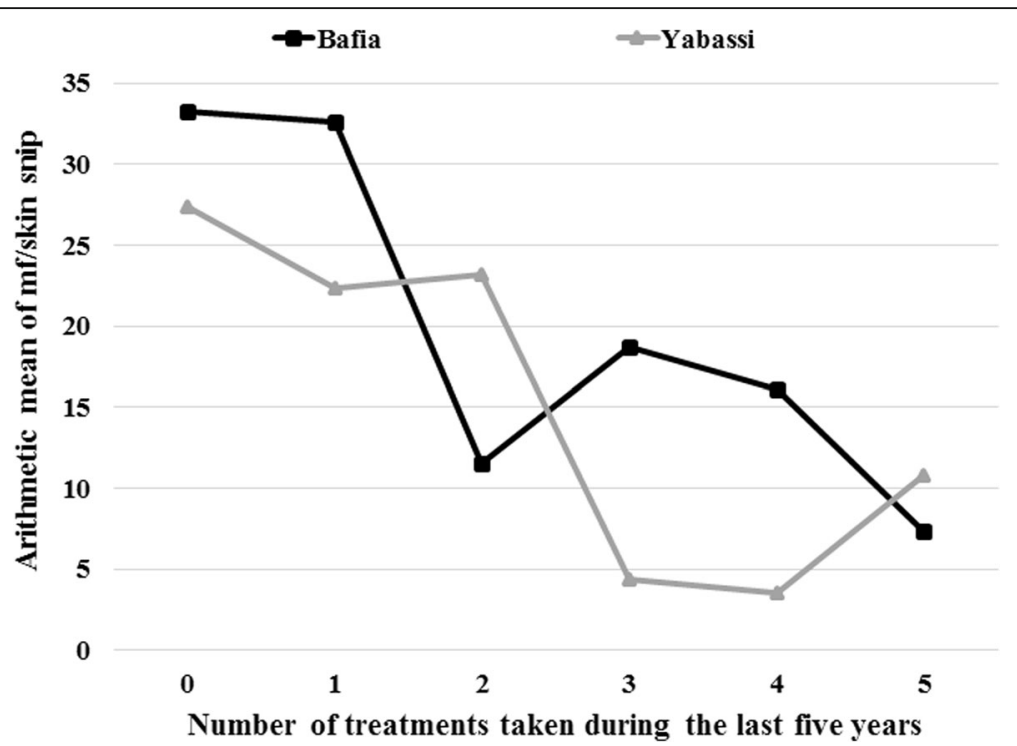

Fig. 10 Arithmetic mean of microfilaria per skin snip according to the number of ivermectin treatment taken during the last five years among carriers in Bafia and Yabassi health districts

hypothesized that ivermectin would enable to eliminate onchocerciasis in the study areas if CDTI were properly implemented as demonstrated in Mali and Nigeria $[44,45]$. An improvement in therapeutic coverage is a major requirement in these areas with high baseline intensities of infection.

As observed in previous studies, males were more affected than females probably due to their socioeconomic activities [46-48]. In addition, due to their prolonged exposition to the bites of blackflies, the oldest participants have more nodules than their youngest counterparts; meanwhile their adherence to treatment could explain their lowest intensity of infection. This adherence is probably motivated by their awareness about the consequences of the disease.

The localization of nodules was comparable to previous studies [33-35, 49], especially in Biatsota and Ngongol I. Onchocercal skin disease was more frequent in two communities (Bonadissake and Ndogpoo) where lower limb depigmentation, acute and chronic onchodermatitis were found.

\section{Conclusions}

After more than 15 years of CDTI, onchocerciasis is still mesoendemic in the communities surveyed as part of this study. Additional efforts should be made to improve the CDTI therapeutic coverage in all communities so as to greatly reduce the prevalence and the microfilarial densities in order to eliminate this debilitating disease in these two CDTI-projects. Further studies targeting community therapeutic coverage, CDTI process and entomological studies would provide better insights into our understanding of the persistence of the disease as described in this study.

\section{Additional file}

Additional file 1: Datasets of Bafia and Yabassi health districts

supporting this study. (XLSX $114 \mathrm{~kb})$

\section{Abbreviations}

APOC: African Programme for Onchocerciasis Control; ARES-CCD: Académie de Recherche et d'Enseignement Supérieur-Commission de la Coopération au Développement, Belgique; CDD: Community-directed distributors;

CDTI: Community-directed treatment with ivermectin; Cl: Confidence interval; CMFL: Community microfilarial load; CRFilMT: Centre for Research on Filariasis and other Tropical Diseases, Cameroon; HD: Health district; MDA: Mass drug administration; mf/ss: Microfilariae per skin snip; NOCP: National Onchocerciasis Control Programme, Cameroon; WHO: World Health

Organization

\section{Acknowledgements}

The authors thank the former African Programme for Onchocerciasis Control (APOC) through the National Onchocerciasis Control Programme for having provided the data of epidemiological evaluations conducted in 2011. We also thank the lab technicians Bopda Jean, Batif Emmanuel and Mbickmen Tchana Steve who helped us to collect and analyze skin snips, the staff of Bafia and Yabassi health districts, the heads of the surveyed communities, and the participants for their cooperation.

\section{Funding}

This study was funded by the Belgian university cooperation (http:// www.ares-ac.be/fr/cooperation-au-developpement) through the PRD2013 collaborative project between Université catholique de Louvain, Université Libre de Bruxelles, the University of Buea, the Centre for Research on Filariasis and other Tropical Diseases

(CRFilMT) and the Ministry of Public Health of Cameroon.

\section{Availability of data and materials}

The datasets supporting the conclusions of this article are included within the article and its Additional file 1. 


\section{Authors' contributions}

GRK participated to the design of experiments, collected field data, performed statistical analyses and drafted the manuscript. FDD participated to the design of experiments and helped to draft the manuscript. HND participated to the design of experiments, provide assistance in the statistical analyses and drafted the manuscript. BDB provided previous data and helped to draft the manuscript. SG participated in the conception and the design of the study, and helped to draft the manuscript. JS conceived the study, designed the experiments, and helped to draft the manuscript. $\mathrm{HZ}$ provided previous data and helped to draft the manuscript. MB provided previous data and helped to draft the manuscript. JK conceived and the coordinated the study, designed the experiments, and helped to draft the manuscript. AR conceived the study, designed the experiments, and helped to draft the manuscript. All authors read and approved the final manuscript.

\section{Competing interests}

The authors declare that they have no competing interests.

\section{Consent for publication}

Not applicable.

\section{Ethics approval and consent to participate}

An ethical clearance was obtained from the National Ethics Committee for Human Health Research (N²015/01/543/CE/CNRESH/SP) and an administrative authorization was granted by the Ministry of Public Health of Cameroon ( $\left.N^{\circ} 631-1315\right)$ prior to the beginning of the surveys. The study was also approved by the Ethics committee of the Medical Faculty of Université catholique de Louvain, Belgium. Objectives and schedules of the study were explained to community leaders and to all eligible individuals. Because of low literacy rate in most of the surveyed communities, a written agreement was not requested. Verbal agreements were obtained from those who agreed to participate, under the discretion of community leaders. Approval of parents or legal guardians of minors was obtained before any procedure. The study supervisor was responsible to record agreements and attribute individual code to each participant for anonymous data analysis. Participation was entirely voluntary and any individual (or parent of a child) was free to opt out of examination without fear of retaliation from their community leaders and programme personnel.

\section{Author details}

'Ministry of Public Health, №8, Rue 3038 quartier du Lac, Yaoundé, Cameroon. ${ }^{2}$ Centre for Research on Filariasis and other Tropical Diseases (CRFilMT), P.O. Box 5797, Yaoundé, Cameroon. ${ }^{3}$ Institut de Recherche Expérimentale et Clinique, Faculté de santé publique, Université catholique de Louvain, Clos Chapelle-aux-champs 30 bte B1.30.13 BE-1200, Brussels, Belgium. ${ }^{4}$ Institute of Biology of Molecular Medicine, Université Libre de Bruxelles, Rue des professeurs Jeener et Brachet 12 BE-6041 Gosselies, Brussels, Belgium. ${ }^{5}$ Faculty of Medicine and Biomedical Sciences, University of Yaoundé 1, P.O. Box 1364, Yaoundé, Cameroon. ${ }^{6}$ Molecular and Cell Biology Laboratory, Department of Biochemistry and Molecular Biology, University of Buea, P.O. Box 63, Buea, Cameroon. 'World Health Organization, African Programme for Onchocerciasis Control (APOC), 01 P.O. Box 549, Ouagadougou 01, Burkina Faso. ${ }^{8}$ Institut de Recherche pour le Développement (IRD), IRD UMI 233 TransVIHMI - Université Montpellier INSERM U1175, 911 avenue Agropolis, P.O. Box 6450134394 Montpellier Cedex 5, France.

\section{Received: 21 September 2016 Accepted: 2 November 2016}

\section{Published online: 14 November 2016}

\section{References}

1. Remme JHF, Feenstra P, Lever PR, Medici AC, Morel CM, Noma M, et al. Tropical diseases targeted for elimination: Chagas disease, lymphatic filariasis, onchocerciasis, and leprosy. In: Jamison DT, Breman JG, Measham AR, Alleyne G, Claeson M, Evans DB, et al., editors. Disease control priorities in developing countries. 2nd ed. Washington (DC): Oxford University Press and The World Bank; 2006. p. 433-50.

2. Zoure HG, Noma M, Tekle AH, Amazigo UV, Diggle PJ, Giorgi E, et al. The geographic distribution of onchocerciasis in the 20 participating countries of the African Programme for Onchocerciasis Control: (2) pre-control endemicity levels and estimated number infected. Parasit Vectors. 2014;7:326.
3. Plaisier AP, van Oortmarssen GJ, Remme J, Habbema JD. The reproductive lifespan of Onchocerca volvulus in West African savanna. Acta Trop. 1991;48:271-84.

4. Duke BO. The population dynamics of Onchocerca volvulus in the human host. Trop Med Parasitol. 1993;44:61-8.

5. Murdoch ME. Onchodermatitis. Curr Opin Infect Dis. 2010;23:124-31.

6. Murdoch ME, Asuzu MC, Hagan M, Makunde WH, Ngoumou P, Ogbuagu KF, et al. Onchocerciasis: the clinical and epidemiological burden of skin disease in Africa. Ann Trop Med Parasitol. 2002;96:283-96.

7. Hoerauf A, Buttner DW, Adjei O, Pearlman E. Onchocerciasis. BMJ. 2003; 326:207-10

8. Resnikoff S, Keys TU. Future trends in global blindness. Indian J Ophthalmol. 2012;60:387-95.

9. Tchounkeu YF, Onyeneho NG, Wanji S, Kabali AT, Manianga C, Amazigo UV, et al. Changes in stigma and discrimination of onchocerciasis in Africa. Trans R Soc Trop Med Hyg. 2012;106:340-7.

10. Evans TG. Socioeconomic consequences of blinding onchocerciasis in west Africa. Bull World Health Organ. 1995;73:495-506.

11. WHO. The involvement of community-directed distributors of ivermectin in other health and development activities: report of a multi-country study. UNICEF/UNDP/World Bank/WHO Special Programme for Research and Training in Tropical Diseases. 2003. p. 1-47.

12. WHO. Community directed interventions for major health problems in Africa: a multi-country study. UNICEF/UNDP/World Bank/WHO Special Programme for Research and Training in Tropical Diseases. 2008. p. 1-132.

13. Hopkins A, Boakye AB. Onchocerciasis. In: Janine MH, Selendy, editors. Water and sanitation-related diseases and the environment: challenges, interventions, and preventive measures, vol. 1. New Jersey: John Wiley \& Sons, Inc; 2011. p. 133-49.

14. WHO. African programme for onchocerciasis control: progress report, 20132014. Wkly Epidemiol Rec. 2014;89:551-60.

15. Katabarwa M, Richards F. Twice-yearly ivermectin for onchocerciasis: the time is now. Lancet Infect Dis. 2014;14:373-4.

16. WHO. Progress towards eliminating onchocerciasis in the WHO region of the Americas: verification by WHO of elimination of transmission in Colombia. Wkly Epidemiol Rec. 2013;88:381-5.

17. WHO. Elimination of onchocerciasis in the WHO region of the Americas: Ecuador's progress towards verification of elimination. Wkly Epidemiol Rec. 2014;89:401-5.

18. WHO. Progress toward eliminating onchocerciasis in the WHO Region of the Americas: verification of elimination of transmission in Mexico. Wkly Epidemiol Rec. 2015;90:577-81.

19. CDC. Progress toward elimination of onchocerciasis in the Americas: 19932012. MMWR Morb Mortal Wkly Rep. 2013;62:405-8.

20. Rodriguez-Perez MA, Fernandez-Santos NA, Orozco-Algarra ME, RodriguezAtanacio JA, Dominguez-Vazquez A, Rodriguez-Morales KB, et al. Elimination of onchocerciasis from Mexico. PLoS Negl Trop Dis. 2015;9:e0003922.

21. WHO. Onchocerciasis: elimination is feasible. Wkly Epidemiol Rec. 2009; 84:382-3.

22. Diawara L, Traore MO, Badji A, Bissan Y, Doumbia K, Goita SF, et al. Feasibility of onchocerciasis elimination with ivermectin treatment in endemic foci in Africa: first evidence from studies in Mali and Senegal. PLoS Negl Trop Dis. 2009;3:e497.

23. Katabarwa MN, Eyamba A, Nwane P, Enyong P, Yaya S, Baldiagai J, et al. Seventeen years of annual distribution of ivermectin has not interrupted onchocerciasis transmission in North Region. Cameroon Am J Trop Med Hyg. 2011;85:1041-9.

24. Tekle AH, Zoure HG, Noma M, Boussinesq M, Coffeng LE, Stolk WA, et al. Progress towards onchocerciasis elimination in the participating countries of the African Programme for Onchocerciasis Control: epidemiological evaluation results. Infect Dis Poverty. 2016;5:66.

25. WHO. African Programme for Onchocerciasis Control: report of the sixth meeting of national task forces, October 2009. Wkly Epidemiol Rec. 2010;85:23-8.

26. Nana-Djeunga HC, Bourguinat C, Pion SD, Bopda J, Kengne-Ouafo JA, Njiokou F, et al. Reproductive status of Onchocerca volvulus after ivermectin treatment in an ivermectin-naive and a frequently treated population from Cameroon. PLoS Negl Trop Dis. 2014;8:e2824.

27. Osei-Atweneboana MY, Eng JK, Boakye DA, Gyapong JO, Prichard RK. Prevalence and intensity of Onchocerca volvulus infection and efficacy of ivermectin in endemic communities in Ghana: a two-phase epidemiological study. Lancet. 2007;369:2021-9. 
28. Pion SD, Nana-Djeunga HC, Kamgno J, Tendongfor N, Wanji S, Njiokou F, et al. Dynamics of Onchocerca volvulus microfilarial densities after ivermectin treatment in an ivermectin-naive and a multiply treated population from Cameroon. PLoS Negl Trop Dis. 2013;7:e2084.

29. Boussinesq M, Demanga-Ngangue, Richard P, Lele D, Cot S, Chippaux JP. Etude clinique et parasitologique de l'onchocercose dans huit villages de la vallée du Mbam. Bull lias doc OCEAC. 1992; 100:26-31.

30. Gardon J, Boussinesq M, Kamgno J, Gardon-Wendel N, Demanga N, Duke $\mathrm{BO}$. Effects of standard and high doses of ivermectin on adult worms of Onchocerca volvulus: a randomised controlled trial. Lancet. 2002;360:203-10.

31. Kamgno J, Gardon J, Gardon-Wendel N, Demanga N, Duke BO, Boussinesa M. Adverse systemic reactions to treatment of onchocerciasis with ivermectin at normal and high doses given annually or three-monthly. Trans R Soc Trop Med Hyg. 2004;98:496-504.

32. GTNO. Rapport technique annuel 2014 du Groupe de Travail National de lutte contre l'Onchocercose du Cameroun. 2015. p. 70.

33. Albiez EJ. Effects of a single complete nodulectomy on nodule burden and microfilarial density two years later. Trop Med Parasitol. 1985;36:17-20.

34. Albiez EJ, Buttner DW, Duke BO. Diagnosis and extirpation of nodules in human onchocerciasis. Trop Med Parasitol. 1988;39 Suppl 4:331-46.

35. Ngoumou P, Walsh JF, Mace JM. A rapid mapping technique for the prevalence and distribution of onchocerciasis: a Cameroon case study. Ann Trop Med Parasitol. 1994;88:463-74.

36. Prost A, Prod'hon J. Le diagnostic parasitologique de l'onchocercose: revue critique des méthodes en usage. Med Trop. 1978;38:519-32.

37. BUCREP. Projections démographiques du troisième Recensement Général de la Population et de l'Habitat (3ème RGPH) du Cameroun. 3rd ed. 2010. p. 91.

38. Prost A, Hervouet JP, Thylefors B. Les niveaux d'endémie de l'onchocercose. Bull World Health Organ. 1979;57:655-62.

39. Stolk WA, Walker M, Coffeng LE, Basanez MG, de Vlas SJ. Required duration of mass ivermectin treatment for onchocerciasis elimination in Africa: a comparative modelling analysis. Parasit Vectors. 2015;8:552.

40. APOC. Conceptual and operational framework of onchocerciasis elimination with ivermectin treatment. 2010. p. 24.

41. Brieger WR, Okeibunor JC, Abiose AO, Wanji S, Elhassan E, Ndyomugyenyi R, et al. Compliance with eight years of annual ivermectin treatment of onchocerciasis in Cameroon and Nigeria. Parasit Vectors. 2011:4:152.

42. Brieger WR, Okeibunor JC, Abiose AO, Ndyomugyenyi R, Kisoka W, Wanji S, et al. Feasibility of measuring compliance to annual ivermectin treatment in the African Programme for Onchocerciasis Control. Trop Med Int Health. 2007;12:260-8.

43. Wanji S, Kengne-Ouafo JA, Esum ME, Chounna PW, Adzemye BF, Eyong JE, et al. Relationship between oral declaration on adherence to ivermectin treatment and parasitological indicators of onchocerciasis in an area of persistent transmission despite a decade of mass drug administration in Cameroon. Parasit Vectors. 2015;8:667.

44. Traore MO, Sarr MD, Badji A, Bissan Y, Diawara L, Doumbia K, et al. Proof-ofprinciple of onchocerciasis elimination with ivermectin treatment in endemic foci in Africa: final results of a study in Mali and Senegal. PLoS Negl Trop Dis. 2012;6:e1825.

45. Tekle AH, Elhassan E, Isiyaku S, Amazigo UV, Bush S, Noma M, et al. Impact of long-term treatment of onchocerciasis with ivermectin in Kaduna State, Nigeria: first evidence of the potential for elimination in the operational area of the African Programme for Onchocerciasis Control. Parasit Vectors. 2012;5:28.

46. Newell ED, Ndimuruvugo N. Endémicité et manifestations cliniques de I'onchocercose dans la province de Rutana, Burundi. Bull Soc Pathol Exot. 1997;90:107-10.

47. Newell ED, Hicuburundi B, Ndimuruvugo N. Endémicité et manifestations cliniques de l'onchocercose dans la province de Burundi, Burundi. Trop Med Int Health. 1997:2:218-26

48. Ameh GI, Ukatu VE, Adamu T, Muazu S. Skin microfilariae and clinical manifestations of onchocerciasis in some villages at Kwanji district of Kebbi state, Nigeria. Jos J Med. 2008;3:33-6.

49. Katabarwa M, Onapa AW, Nakileza B. Rapid epidemiological mapping of onchocerciasis in areas of Uganda where Simulium neavei $s$ is the vector. East Afr Med J. 1999;76:440-6.

\section{Submit your next manuscript to BioMed Central and we will help you at every step:}

- We accept pre-submission inquiries

- Our selector tool helps you to find the most relevant journal

- We provide round the clock customer support

- Convenient online submission

- Thorough peer review

- Inclusion in PubMed and all major indexing services

- Maximum visibility for your research

Submit your manuscript at www.biomedcentral.com/submit

) Biomed Central 